\title{
The responses of an able bodied person to wheelchair training: a case study
}

Department of PE and

Sports Science,

Loughborough

University,

Loughborough,

Leicestershire LE11

3TU, United Kingdom

H K A Lakomy

$\mathrm{T}$ Williams

Correspondence to: Dr Henryk Lakomy.

Accepted for publication 13 September 1995

\begin{abstract}
Objective-To examine the responses of a previously untrained, able bodied male to a 10 month training programme in a wheelchair.

Methods-Physiological indices and performance times were measured over the 10 month period during periods of general conditioning, specific conditioning, and competition.

Results-Although both peak oxygen uptake and maximum heart rate increased it was found that the main contribution to improvements in performance was from increased pushing economy. The value of peak oxygen uptake for the subject was within the normal range for paraplegics; however, maximum ventilation exceeded the levels normally achieved by paraplegics. At the conclusion of the study the subject successfully completed a wheelchair marathon in a time of $2 \mathrm{~h} 9 \mathrm{~min}$ at an average speed of $5.17 \mathrm{~m} \mathrm{~s}^{1}$.

Conclusions-It was possible for an able bodied person with no previous experience in a wheelchair to successfully compete in a wheelchair marathon with only 10 months training. The main contribution to the improvement in performance was from increased pushing economy.

(Br F Sports Med 1996;30:236-237)
\end{abstract}

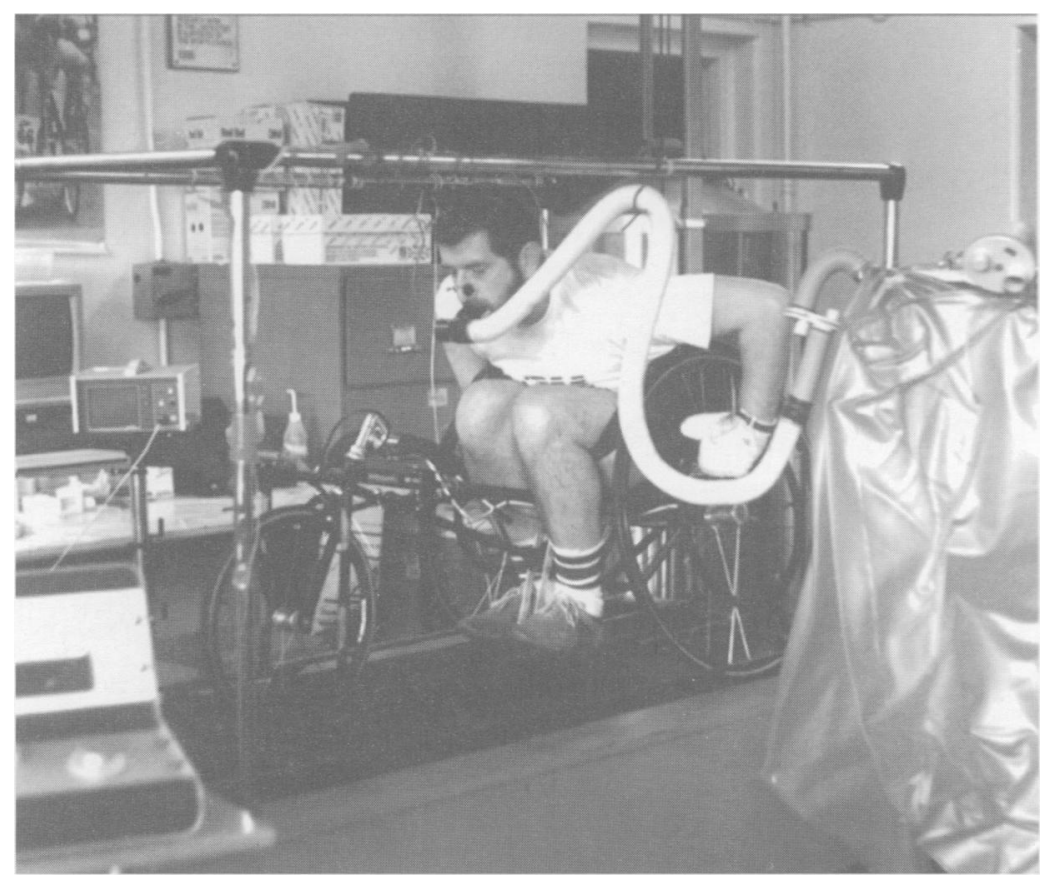

Figure 1 The treadmill test system.
As part of a project to examine the profile of responses of previously untrained wheelchair users to the demands of training for a marathon, this study set out to investigate the "normal" response of a 42 year old able bodied male, with no previous experience of wheelchair pushing, to 10 months of training in a wheelchair, against whom the responses of the wheelchair-bound users could be compared. During the training period several of the physiological characteristics of the performer were monitored. At the end of the study period the subject completed a marathon race.

The subject, who usually jogged once or twice per week, undertook a structured training programme in a racing wheelchair. The average monthly training volume is shown in the table. The table also shows the volume of training performed during the four phases of the training programme. Training pace both on the road and on the rollers was steadily increased each month, as was the average distance pushed per session.

Throughout the study, $10 \mathrm{~km}$ road time trials were used to monitor performance changes and tests were regularly undertaken in the laboratory using the system described by Lakomy et $a l^{1}$. The system, shown in fig 1, allowed the subject to propel his own racing wheelchair on a motorised treadmill which was adapted for use by wheelchairs. A slider mechanism on the treadmill allowed freedom of movement of the wheelchair forwards and backwards but restricted sideways movement. The speed of the treadmill could be altered at any time by the wheelchair athlete by depressing large format switches mounted on the wheelchair.

Figure 2 shows the steady increase in $10 \mathrm{~km}$ road time trial pushing performance, expressed as average speed, throughout the study. By the end of the study, $10 \mathrm{~km}$ time trial speed had improved from 3.38 to $5.51 \mathrm{~m} \mathrm{~s}^{-1}$, an improvement of $63.0 \%$.

In the laboratory tests the subject propelled his wheelchair on the treadmill at a constant speed which was incremented every $4 \mathrm{~min}$ until volitional exhaustion was reached. During the final minute of each speed, expired air was collected in a Douglas bag for the determination of oxygen uptake and ventilation. Peak oxygen uptake and maximum ventilation were determined from the final expired air sample. Throughout each test heart rate was monitored. As anticipated both oxygen uptake $(r=$ $0.92)$ and heart rate $(r=0.94)$ were found to be linearly related to exercise intensity, expressed as pushing speed. 
Table 1 The training programme showing the average speed $\left(\mathrm{km} \mathrm{h}^{-1}\right)$ and distance $(\mathrm{km})$ pushed per session, and a description of the phases of training regimen.

\begin{tabular}{|c|c|c|c|c|}
\hline \multirow[t]{2}{*}{ Month } & \multicolumn{2}{|l|}{ Rollers } & \multicolumn{2}{|l|}{ Road } \\
\hline & Ave speed $\left(\mathrm{km} \mathrm{h}^{-1}\right)$ & Ave distance $(\mathrm{km})$ & Ave speed $\left(\mathrm{km} \mathrm{h}^{-1}\right)$ & Ave distance $(\mathrm{km})$ \\
\hline $\begin{array}{l}1 \text { November } \\
2 \text { December } \\
3 \text { January } \\
4 \text { February }\end{array}$ & $\begin{array}{l}8.97 \\
9.87 \\
10.8 \\
11.09\end{array}$ & $\begin{array}{l}2.85 \\
3.66 \\
4.64 \\
4.7\end{array}$ & $\begin{array}{l}10.78 \\
12.77 \\
13.85 \\
13.76\end{array}$ & $\begin{array}{l}11.93 \\
11.4 \\
8.95 \\
8.76\end{array}$ \\
\hline $\begin{array}{l}5 \text { March } \\
6 \text { April } \\
7 \text { May } \\
8 \text { June }\end{array}$ & $\begin{array}{l}13.29 \\
13.41 \\
12.89 \\
14.8\end{array}$ & $\begin{array}{l}5.02 \\
5.1 \\
4.09 \\
4.14\end{array}$ & $\begin{array}{l}13.2 \\
16.6 \\
16.8 \\
17.18\end{array}$ & $\begin{array}{l}16.05 \\
11.82 \\
12.75 \\
14.26\end{array}$ \\
\hline $\begin{array}{l}9 \text { July } \\
10 \text { August } \\
11 \text { September }\end{array}$ & $\begin{array}{l}15.0 \\
12.95 \\
12.8\end{array}$ & $\begin{array}{l}5.08 \\
2.17 \\
2.15\end{array}$ & $\begin{array}{l}16.7 \\
15.46 \\
18.85\end{array}$ & $\begin{array}{l}13.11 \\
20.73 \\
25.75\end{array}$ \\
\hline
\end{tabular}

Phase 1 - Introduction (3 weeks)

Lived in an "everyday" wheelchair to accustom hands, arms, and shoulder girdle to pushing stresses in an effort to avoid injuries.

Phase 2 - General conditioning (November to end of February)

Concentrated on increasing volume of work and improving pushing skills.

Established a weekly training pattern (six daily wheelchair training sessions, three weekly weight training sessions, and one rest day).

Forearms always fatigued first.

Trauma injury to right forearm (introduced to high intensity sprinting too quickly).

Phase 3 - Specific conditioning (March to end of June)

Concentrated on increasing speed. Roads used for conditioning.

Rollers used for skill sessions, concentrating on consistent pushing at higher speeds.

Right forearm injury recurring and started swimming as alternate training ( $200 \mathrm{yds}$ per session). Weekly training pattern of training twice per day (six swimming sessions, six wheelchair training sessions, three weight training sessions, and one rest day).

Phase 4 - Competition (July to end of September)

Concentrated on increasing volume to marathon distance, increasing speed, and improving pushing skills.

No weight training, and rollers used only for skill sessions.

Weekly training pattern of training twice per day (six swimming sessions, six wheelchair sessions, and one rest day).

The maximum speeds achieved in each treadmill test are also shown in fig 2. After 6 months of training no further improvement in maximum test speed was achieved, despite the continuing increase in road performance.

In contrast to the increase in pushing performance, both on the treadmill $(48.7 \%)$ and the road (63\%), peak oxygen uptake improved by only $12.9 \%$. from 2.49 to 2.81 litres $\mathrm{min}^{-1}$. The value of 2.81 litres $\mathrm{min}^{-1}$ is at the upper end of the normal range for paraplegics measured in our laboratory. It is clear therefore that only some of the improvements seen in performance can be accounted for by the increased peak oxygen uptake of the individual (fig 3). In an attempt to discover the major cause for the improvement in performance the economy of pushing was examined.

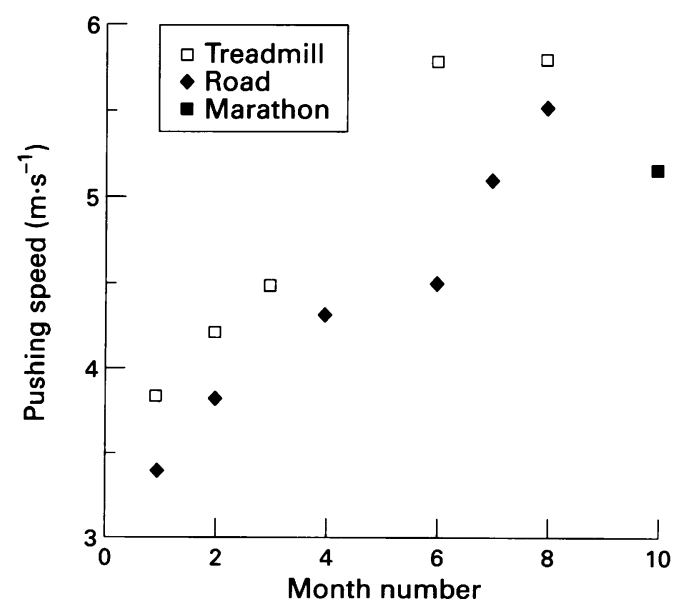

Figure 2 Average pushing speed on the treadmill, during the $10 \mathrm{~km}$ time trial and the marathon.

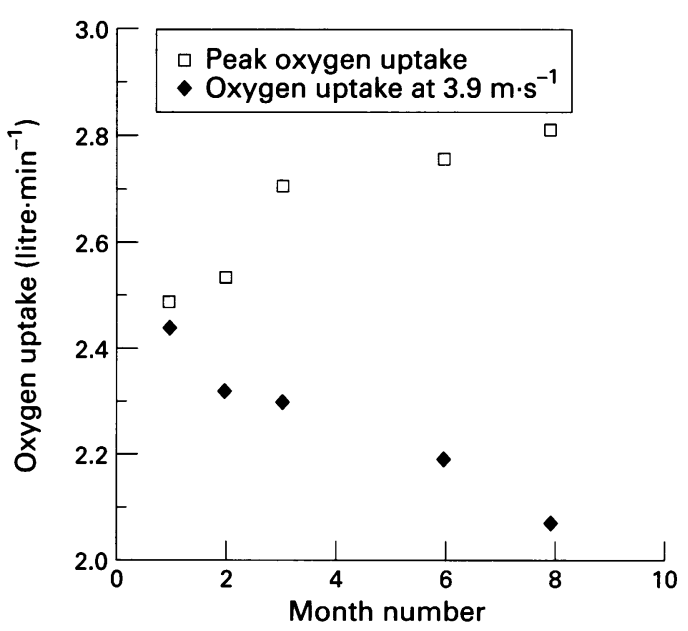

Figure 3 Peak oxygen uptake and pushing economy on the treadmill (expressed as the oxygen uptake at a constant pushing speed of $3.9 \mathrm{~m} \mathrm{~s}^{-1}$ ) during the training period.

Pushing economy was defined as the energy cost (oxygen uptake) of wheelchair propulsion at a constant fixed speed. The speed chosen was $3.9 \mathrm{~m} \mathrm{~s}^{-1}$. Figure 3 also shows the oxygen uptake at $3.9 \mathrm{~m} \mathrm{~s}^{-1}$ for each of the tests. It is clear that the energy required to maintain this pushing speed decreased with training with evidence of a plateau being reached after about 6 months. The improvement in economy over the training period was approximately $20.1 \%$.

In the first test, maximum heart rate was 174 beats $\mathrm{min}^{-1}$. This rose to 181 beats $\mathrm{min}^{-1}$ by the third month, an increase of $3.9 \%$. Thereafter the training did not result in any further increase in maximum heart rate. These values of maximum heart rate fall within the normal range for paraplegics.

It is clear from the study that for this able bodied subject ventilation was not the limiting factor for performance. Maximum ventilation, the highest value attained during the incremental test, remained at approximately 130 litres throughout the study despite the $63.0 \%$ improvement in performance. Sufficient ventilation is often a limitation to performance for high spinal lesion level paraplegics and tetraplegics. The able bodied performer has, therefore, a clear advantage over these individuals.

At the conclusion of the training period the subject successfully competed in a wheelchair marathon which he completed in a time of $2 \mathrm{~h}$ $9 \mathrm{~min}$ at an average speed of $5.17 \mathrm{~m} \mathrm{~s}^{-1}$. A time of $2 \mathrm{~h} 30 \mathrm{~min}$ is regarded as a very good time for a first wheelchair marathon; therefore the time achieved was excellent.

\section{Conclusions}

It was possible for an able bodied person with no previous experience in a wheelchair to successfully compete in a wheelchair marathon with only 10 months training. During the training period the main contribution to the improvement in performance was from increased pushing economy. Increased peak oxygen uptake and maximum heart rate accounted for a smaller proportion of the improvement in performance.

1 Lakomy HKA, Campbell I, Williams C. Treadmill performance and selected physiological characteristics of wheelchair athletes. Br f Sports Med 1987;21:130-3. 